\begin{abstract}
S
(This section of the JouRnal. is published in collaboration with the abstracting Journal, Abstracts of World Medicine, published by the British Medical Association. The abstracts are divided into the following sections : toxicology ; industrial physiology ; industrial lung disease ; industrial skin diseases ; accidents and orthopaedic surgery ; industrial ophthalmology ; environment ; ger.eral. Not all sections will necessarily be represented in any one issue)
\end{abstract}

\section{INDUSTRIAL TOXICOLOGY}

Berylliosis. Summary and survey of All Clinical Types Observed in a Twelve-year Period. DENARDI, J. M., VAN ORdSTRAND, H. S., CURTIS, G. H., and Zielinski, J. (1953). Arch. industr. Hyg., 8, 1.

During the 12 years $1940-51$, the authors have observed and treated 468 patients suffering from various types of beryllium intoxication-dermatitis, tracheobronchitis, and pneumonitis. The cases were observed at three plants in the Lorain area of Ohio engaged in the extraction and processing of beryllium, in which a total of 3,027 persons were employed during the period, the number employed at the end of that time being 369 . [From the figures given it is clear that the labour was largely migratory and the labour turnover considerable, which may have been partly due to fluctuation in demand for military purposes.]

Acute dermal and ocular manifestations appeared in 209 persons ; minor and major respiratory-tract involvement occurred in 222 persons ; the chronic form of the disease was represented by 2 dermal and 35 pulmonary cases.

Three broad types of berylliosis of the skin and mucous membranes were observed : (1) acute dermatitis with and without conjunctivitis and mucositis of the nasopharynx ; (2) beryllium ulcer; and (3) cutaneous granuloma. The dermatitis presented either as a primary contact type (63 cases) involving exposed surfaces or as an allergic eczematous type (146 cases) due to hypersensitization to beryllium salts and involving exposed surfaces, the genito-crural region, and the lower extremities. The manifestations occurred acutely after 7 to 14 days' exposure to soluble beryllium salts, but recovery was complete in all cases in a like period after removal from exposure and treatment with antihistaminics locally and systemically.

Acute tracheobronchitis, which was due mainly to exposure to fumes, mists, and dusts of beryllium fluoride, ammonium beryllium fluoride, and beryllium sulphate, occurred in 129 workmen. Clinical and radiographic recovery was complete in all cases.

Among 93 cases of acute pulmonary berylliosis, death occurred in 10. Where the exposure was massive the disease appeared after 72 hours, but after less intensive exposure the onset was insidious over a period of several weeks. Radiographic changes appeared 1 to 3 weeks after the onset of symptoms and varied with the stage and intensity of the disability. The chronological sequence of these changes was: (1) diffuse bilateral haziness, usually of the lower lung fields ; (2) irregular soft parenchymal infiltration; and (3) discrete and conglomerate nodules.

Chronic berylliosis was observed in 35 cases. The onset was usually delayed for a period ranging from a few months to several years after initial exposure-in one case for 11 years. It is of considerable interest that 12 of these cases were classified as non-occupational, 8 being attributed to contact with fumes and dust in a zone within $\frac{3}{4}$ mile $(1.2 \mathrm{~km}$.) of the plant and 4 due to handling contaminated working clothes.

The authors have hitherto regarded the following as essential for the diagnosis of chronic berylliosis : (1) a history of exposure to the dusts or fumes of beryllium compounds; (2) characteristic pulmonary syndrome, with diminution of pumonary function ; (3) radiological evidence of granulomatosis ; and (4) positive histological and chemical findings on lung biopsy. However, a patch test in which the beryllium ion is regarded as the sensitizing allergen in both skin and pulmonary manifestations has recently been shown to be reliable and will in future obviate the necessity of lung biopsy.

In view of the lack of effective or specific therapy, especially for the chronic pulmonary disease, preventive measures are most important and in the plants concerned have already achieved excellent results. A. Meiklejohn

\section{Morphological Alterations in the Brain after Intoxication with Parathion ( $p$-Nitrophenyldiethylthiophosphate). [In English]. SiedeK, H., and Thaler, H. (1952). Arch. int. Pharmacodyn., 91, 194.}

In the last few years "parathion" has been widely used as an insecticide in agriculture. In acute poisoning with this insecticide central nervous symptoms predominate. The present study, made at the First Medical Clinic, Vienna University, records the effect of acute and chronic poisoning in dogs, 7 of which were given parathion in doses varying from $8 \mathrm{mg}$. per $\mathrm{kg}$. body weight to a total of $98 \mathrm{mg}$. per $\mathrm{kg}$.; in the latter case the dog survived for 22 days with the help of atropine, which 
eliminated acute toxicity. Animals which died from parathion poisoning showed extensive hyperaemia and haemorrhages in all parts of the brain and spinal cord. Degeneration of ganglionic cells was also present within 30 hours after the first dose of parathion, and after 22 days degeneration of the myelin sheaths was noted. These changes do not appear to be related to the cardiovascular disturbances.

Derek R. Wood

Disorder of the Nervous System in Workers with Tricresyl Phosphate. Bock, E., Bocková, V., Kamení, M., SAHÁNeK, O., and StanêK, J. (1952). Lék. Listy, 7, 490.

At the Neurological and Psychological Clinics of the University of Brno, Czechoslovakia, 59 workers engaged in the manufacture of plastic materials and exposed to the toxic action of tricresyl phosphate, either by absorption through the skin or by inhalation of vapour (or both), were examined by the authors. They found that prolonged exposure may result in a variety of symptoms, mainly related to the automatic nervous system, such as hyperhidrosis, dermographism, trophic disorders, and vasomotor disturbances (with hypotension); other neurological symptoms included polyneuritis (in 15 of their cases, or $25 \%$ ), insomnia, headaches, and neurasthenia, while there were also signs of the involvement of the extrapyramidal system (in workers under the age of 45) and of the pyramidal tracts. It would appear that tricresyl phosphate absorbed through the skin predominantly affects the peripheral nervous system, whereas by inhalation it more frequently causes lesions of the central nervous system. The autonomic nervous system seems to be affected whatever the route of absorption. Symptoms of mental disturbance-emotional instability, and paranoid traits-occurred fairly frequently.

Suggestions are made for reducing the exposure of workers to tricresyl phosphate, and general hygienic measures are recommended. Catherine Schöpflin

Coproporphyrinuria. Study of its Usefulness in Evaluating Lead Exposure. Pinto, S. S., EInert, C., Roberts, W. J., Winn, G. S., and Nelson, K. W. (1952). Arch. industr. Hyg., 6, 496.

One of the "screening" methods hitherto used to discover workers suffering from lead poisoning has been that of direct measurement of the concentration of lead in the urine. To determine significant exposure to lead in 124 employees at a lead smelting plant the authors estimated the urinary excretion of coproporphyrin III by the improved method of Schwartz and others (J. Lab. clin. Med., 1951, 37, 843), which showed that the mean normal excretion was $160 \mu \mathrm{g}$. a day [about $11 \mu \mathrm{g}$. per $100 \mathrm{ml}$. of urine]. Of the 124 subjects, 32 were judged to have significant symptoms, but not one had the classical picture of lead poisoning, then or subsequently. Of these 32, $27(84 \%)$ excreted more than $40 \mu \mathrm{g}$. of coproporphyrin per $100 \mathrm{ml}$. of urine, as compared with $21(23 \%)$ of the 92 who had no symptoms. Estimation of the urinary excretion of lead gave less definite results, but estimation of the concentration of lead in the blood showed that in $26(81 \%)$ of the 32 patients with symptoms and in $30(33 \%)$ of the 92 without symptoms the blood level was over $95 \mu \mathrm{g}$. per $100 \mathrm{~g}$. The distribution of cases according to the basophilic aggregation count appeared to be less definite, while the stippled-cell count was of little value. The 4 patients with the most definite symptoms were among the 7 with the highest urinary excretion of coproporphyrin and among the 9 with the highest urinary excretion of lead. In the series as a whole there was little correlation between a raised concentration of lead in the blood and the urinary excretion of coproporphyrin, but there was a correlation between the latter and the urinary excretion of lead. The authors consider that in lead poisoning estimation of the coproporphyrin content of the urine is of more value than other screening methods. No association between blood pressure and years of exposure was observed.

[The symptoms thought to be attributable to lead are neither listed nor discussed. On the validity of these, always a debatable matter, hangs the whole of this comparative study.]

J. N. Agate

\section{AVIATION MEDICINE}

Aero-otitis : Etiologic and Therapeutic Considerations. Trowbridge, B. C. (1953). Eye, Ear, Nose Thr. Monthly, 32, 500.

The physiological and pathological effects of flight on the ear are described, with special reference to the consequences of inadequate ventilation of the middle ear during recompression. Rupture of the tympanic membrane is a rare complication of aero-otitis media. In most cases the signs and symptoms are aural pain, tinnitus, and low-tone deafness, with retraction and congestion of the tympanic membrane and a serosanguinous effusion into the middle-ear cavity. Aspiration of the middle-ear fluid following double puncture of the tympanic membrane with a fine needle is preferred to conservative treatment. It is claimed that recovery is complete in about 4 days and that the early removal of fluid prevents development of adhesions causing permanent impairment of hearing. In the author's view air travel should be discouraged when acute or chronic infection prevents normal functioning of the Eustachian tubes. In cases of recurrent aero-otitis media the possibility of mechanical obstruction should be borne in mind.

J. A. Armstrong

Altitude Stress in Subjects with Impaired Cardio-
respiratory Function. A Comparison of the Responses
of Normal Subjects, Patients with Angina Pectoris, and
Patients with Anemia to Hypoxia. MARBARGR, J. P.,
WECHSBER, P. H., PESTEL, C. V., VAWTER, G. F.,
and FranzBLAU, S. A. (1953). J. Aviat. Med., 24, 263.

The results are reported of an investigation of the circulatory and respiratory responses to hypoxia carried out at the University of Illinois, Chicago, on three groups of subjects : (1) 10 healthy male subjects aged 21 to 27 ; (2) 8 patients aged 47 to 77 with angina pectoris; and 
(3) 14 patients aged 26 to 70 with chronic anaemia. Each subject was studied at ground level and on exposure to simulated altitudes of 10,000 feet $(3,050 \mathrm{~m}$.) and 18,000 feet $(5,480 \mathrm{~m}$.) in a decompression chamber, comprehensive analyses of cardiac and respiratory function being carried out. The normal response to the anoxia so induced included an increase in pulse rate and stroke volume, an increase in " useful work" of the left ventricle, a fall in peripheral resistance to blood flow, a slight fall in systolic and diastolic blood pressures, and maintenance of a normal venous pressure. The respiratory rate showed a tendency to rise with the more severe stress, and the oxygen and carbon dioxide content and oxygen saturation of arterial blood fell, the haematocrit value rose slightly, and minor changes occurred in the electrocardiogram (ECG) which were rapidly reversed by oxygen administration.

In the subjects with angina the blood pressure and pulse pressure were increased on initial examination, peripheral resistance was slightly raised, and there were signs in the ECG of myocardial ischaemia. The changes on exposure to altitude resembled those observed in normal subjects with the exception of an upward trend in both arterial and venous blood pressure. Angina was experienced by some members of this group after 10 minutes at 18,000 feet, and reversal of the changes in the ECG was slower than normal on oxygen administration. In the anaemic subjects at ground level the pulse rate, stroke volume, mean arterial pressure, and venous pressure were increased, peripheral resistance was slightly raised, and arterial oxygen content reduced. Their response to altitude differed from that of the other groups only in that the venous pressure rose significantly, the left ventricular work rate rose more steeply, and the changes in the ECG were reversed more slowly. The rise in cardiac output in all groups was achieved by elevation of both pulse rate and stroke volume.
It is concluded that the risk entailed in the air transport of anaemic and anginal subjects seems slight in modern aircraft, especially if oxygen equipment is available.

$$
\text { D. I. Fryer }
$$

\section{GENERAL}

Effect of Prolonged Exposure to Intense Noise on Hearing Acuity. Sataloff, J. (1953). Arch. Otolaryng. (Chicago), 58, 62.

The author has made an audiographic study, with regular otological examinations of 154 men, all under 50 and the great majority under 40 , who were employed in testing jet-engines and were daily exposed to a continuous noise with an intensity between 90 and 120 decibels for periods up to 5 years. No subjects were included who showed any conduction deafness or who used ear-protectors. The predominant frequencies were below the level of 600 c.p.s.

His conclusions are as follows. (1) Workers in industry who are exposed to continuous, moderately intense, lowfrequency noise may sustain measurable degrees of auditory fatigue daily for many years without suffering any significant degree of permanent hearing impairment. (2) None of the subjects in this study showed any change in hearing acuity in the 1,024 and 2,048 frequency range, and none sustained changes greater than 30 decibels at 4,096 and 8,192 c.p.s. (3) None of the changes could definitely be attributed to the noise being investigated. Subjective hearing loss and tinnitus were rare. It is concluded that, from the observations made in this study so far, the human ear would appear to be more resistant to noise than it is usually thought to be. The author's methods and the apparatus used are described in detail. .F. W. Watkyn-Thomas

\section{Mackenzie Industrial Health Lecture}

The Mackenzie Industrial Health Lecture is arranged biennially by the British Medical Association to commemorate Mr. James Mackenzie, the founder of the Industrial Health Education Society. The 1954 lecture was arranged in conjunction with the Association of
Industrial Medical Officers and given during the provincial meeting of that Association on July 13, by Dr. M. W. Goldblatt. His subject was " Research in Industrial Health in the Chemical Industry ". The lecture will be published in a forthcoming issue of this journal.

\section{Lodging of Recondite Data}

Arrangements have been made whereby the Technical Information and Documents Unit (T.I.D.U.) of the Department of Scientific and Industrial Research will, on the Editor's recommendation, accept the custody of research papers, particularly those touching industry, for which, on account of their length, there is insufficient space in this journal. This mainly concerns ancillary material which, being inessential to the general reader, need not occupy space in the journal, or, possibly, a complete paper of highly specialized interest. It is intended that specialist workers interested should have access to deposited material eithèr in the reading room of the T.I.D.U. or by loan from the Unit at Cunard House, 15, Lower Regent Street, London, S.W.1. 